\title{
Avaliação da sustentabilidade da expansão do perímetro urbano da cidade de Piracicaba - SP por meio de indicadores de farma urbana'
}

\section{Sustainability assessment of the expansion of the urban perimeter of Piracica- ba - SP using indicators of urban form}

Roberto Braga *

\begin{abstract}
Resumo:
Este artigo tem como objetivo a discussão e o desenvolvimento de indicadores para avaliação da sustentabilidade de processos de expansão urbana com base no conceito de forma urbana sustentável. O conceito de forma urbana sustentável reconhece que cidades mais compactas, socioespacialmente diversas e com usos do solo integrados são mais sustentáveis tanto ambiental quanto socialmente. O estudo de caso é a cidade de Piracicaba-SP e são avaliados os perímetros urbanos delimitados nos anos de 2000 e 2013. Foram desenvolvidos e aplicados seis indicadores. Os resultados indicaram que a delimitação do perímetro urbano não atendeu aos padrões de sustentabilidade, bem como houve uma piora dos indicadores no período analisado.
\end{abstract}

\section{Abstract:}

This article aims at discussing and developing sustainability indicators for assessment of urban expansion processes based on the concept of sustainable urban form. The concept of sustainable urban form recognizes that more compact cities, socially diverse and integrated land uses are more sustainable both environmentally and socially. The case study is the city of Piracicaba-SP and are evaluated the urban perimeters delimited in 2000 and 2013. Six indicators were developed and applied. The results indicated that the delimitation of the urban area did not meet the sustainability standards, and there was a worsening of the indicators in the analyzed period.
*Doutor em Geografia Humana pela Universidade de São Paulo (USP). Professor adjunto no Departamento de Planejamento Regional da Universidade Estadual Paulista Júlio de Mesquita Filho (UNESP - Rio Claro).

\section{Palavras-chave:}

cidade sustentável, indicadores ambientais, expansão urbana

Key-Words:

sustainable city, environmental indicators, urban sprawl 
INTRODUÇÃO

rande parte dos problemas sociais, am3 bientais e até econômicos de uma cidade é creditado ao chamado crescimento desordenado. As cidades brasileiras têm crescido espacialmente de maneira aparentemente descontrolada, ocupando áreas ambientalmente frágeis, sem infraestrutura e distantes das fontes de emprego, sobretudo quando se trata de população de mais baixa renda. Os Planos Diretores e seus instrumentos urbanísticos parecem não surtir efeito em proporcionar um crescimento mais equilibrado, social e ambientalmente sustentável. A recente crise hídrica que afeta grandes centros urbanos brasileiros está diretamente relacionada a esse processo, sobretudo a Região Metropolitana de São Paulo, que viu suas áreas de mananciais serem ocupadas regular ou irregularmente. Os desastres ambientais (deslizamentos, inundações etc.) que acometeram áreas periféricas de cidades médias e grandes também reforçam a ideia de que a expansão das áreas urbanas vem se dando de maneira insustentável.

$\mathrm{Na}$ definição da política de desenvolvimento e expansão urbana, a delimitação do perímetro urbano é uma etapa fundamental. É através desse processo que se qualifica o solo municipal para o uso urbano. O perímetro urbano é o componente do macrozoneamento municipal que delimita a zona urbana e, por exclusão, delimita a zona rural. Como bem define Silva (1995), o perímetro qualifica urbanisticamente o solo municipal, preordenando -o ao exercício da função social da cidade.

A delimitação do perímetro urbano é de vital importância para a política urbana e seu ponto de partida. Ao incluir qualquer área dentro do perímetro urbano, a municipalidade assume que essa área está apta a ser urbanizada. Da correta delimitação do perímetro urbano depende a correta aplicação dos demais instrumentos urbanísticos, como o parcelamento e o zoneamento urbano.

Apesar dessa importância, a delimitação do perímetro urbano tem sido um item frequentemente negligenciado no planejamento urbano brasileiro. O próprio Estatuto da Cidade não fazia qualquer referência a esse tema em seu texto original de 2001. O caso mais frequente é o superdimensiona- mento da zona urbana, com a frequente expansão do perímetro urbano, independentemente de haver incremento demográfico ou aumento da demanda efetiva de áreas urbanizáveis no município. O resultado tem sido a geração de vazios urbanos, que promovem a especulação imobiliária com o consequente encarecimento da terra urbana, bem como dificultam e encarecem a implantação de infraestrutura urbana.

Não é exagero afirmar que a delimitação do perímetro urbano é uma questão chave para a sustentabilidade ambiental de uma cidade. A inadequada expansão da zona urbana pode estimular a ocupação de áreas ambientalmente inadequadas na franja periurbana, como as áreas de mananciais e, do mesmo modo, incentivar a dispersão e a fragmentação do tecido urbano. Um tecido urbano disperso e fragmentado aumenta os custos ambientais e sociais da mobilidade urbana, diminuindo sua eficiência eco energética, aumentando a demanda por deslocamentos motorizados e encarecendo o transporte coletivo. Outro efeito adverso da má delimitação do perímetro urbano é o aumento dos custos de implantação da infraestrutura urbana, que são diretamente proporcionais à densidade urbana.

Desse modo, o presente trabalho tem como objetivo desenvolver e discutir indicadores para a avaliação da sustentabilidade dos perímetros urbanos, tendo como estudo de caso a cidade de Piracicaba-SP. A análise será efetuada com base no conceito de forma urbana sustentável, segundo o qual cidades mais compactas, socioespacialmente diversas e com usos do solo integrados são mais sustentáveis tanto ambiental quanto socialmente, na media em que favorecem a eficiência eco-energética e a interação social.

\section{O PERÍMETRO URBANO NO ORDENAMENTO URBANÍSTICO BRASILEIRO}

A primeira referência à necessidade de delimitação de um perímetro urbano pelo município se dá no Código Tributário Nacional (CTN), de 1966 (Lei 6.172/66). Esta lei estabelece que, para a cobrança do Imposto Predial e Territorial Urbano (IPTU), é necessário que o imóvel esteja em zona urbana, ou seja, contido no perímetro urbano delimitado pelo 
município. O CTN estabelece também os requisitos mínimos para delimitação da zona urbana, que são bastante amplos, a saber:

[...] a existência de pelo menos duas melhorias urbanas, dentre: I - meio-fio ou calçamento, com canalização de águas pluviais; II - abastecimento de água; III - sistema de esgotos sanitários; IV - rede de iluminação pública, com ou sem posteamento para distribuição domiciliar; $V$ - escola primária ou posto de saúde a uma distância máxima de 3 (três) quilômetros do imóvel considerado (Lei 6.172/1966. Artigo 32, § 10).

Os requisitos para a qualificação urbanística do solo definidos pelo Código Tributário são muito amplos e em boa parte dos municípios pode abranger inclusive a zona rural, sobretudo nas regiões mais desenvolvidas. Isso fez com que muitos municípios estendessem exageradamente suas zonas urbanas muito além da área efetivamente urbanizada. Alguns chegaram a estender a zona urbana por todo o território, inclusive a área rural, com o intuito de estender a cobrança de IPTU às chácaras de recreio dispersas pelo meio rural. No entanto, se isso em alguma medida favoreceu a arrecadação tributária, também proporcionou o descontrole da ocupação e a fragmentação do tecido urbano.

Mais tarde, a Lei Federal 6.766 de 1979, que regula o parcelamento do solo urbano, determinou que o parcelamento do solo para fins urbanos só seria admitido para imóveis localizados dentro da zona urbana delimitada por lei municipal. No entanto, essa lei não estabeleceu qualquer requisito urbanístico ou ambiental para a delimitação do perímetro urbano, ficando assim os municípios livres para delimitarem seus perímetros urbanos da maneira que lhes aprouvesse.

Em 1988, a Constituição Federal tornou obrigatória a elaboração de Planos Diretores para as cidades com mais de 20 mil habitantes. Esses planos passam a ser os instrumentos básicos de política urbana dos municípios. Assim, a delimitação dos perímetros urbanos passa a ser orientada pelos planos diretores municipais. No entanto essa obrigatoriedade só irá se efetivar em 2001, quando foi aprovado o Estatuto da Cidade, lei 10.257/2001, que regulamentou o capítulo constitucional da política urbana.

O Estatuto da Cidade, porém, não estabeleceu qualquer critério ou diretriz para a delimitação do perímetro urbano, que sequer figurou no rol de instrumentos de política urbana definidos em seu artigo terceiro.

Essa lacuna só foi preenchida onze anos mais tarde. Em 2012, sob influência dos graves desastres ambientais que acometeram o país, sobretudo os municípios da Serra Fluminense, foi editada a Lei Federal 12.608 que institui a política Nacional de proteção e Defesa Civil. Essa Lei, entre outras providências, acrescentou um novo artigo ao Estatuto da Cidade, o artigo 42-B, com a seguinte redação:

Art. 42-B. Os Municípios que pretendam ampliar o seu perímetro urbano após a data de publicação desta Lei deverão elaborar projeto específico que contenha, no mínimo:

I - demarcação do novo perímetro urbano;

II - delimitação dos trechos com restrições à urbanização e dos trechos sujeitos a controle especial em função de ameaça de desastres naturais;

III - definição de diretrizes específicas e de áreas que serão utilizadas para infraestrutura, sistema viário, equipamentos e instalações públicas, urbanas e sociais;

IV - definição de parâmetros de parcelamento, uso e ocupação do solo, de modo a promover a diversidade de usos e contribuir para a geração de emprego e renda;

V - a previsão de áreas para habitação de interesse social por meio da demarcação de zonas especiais de interesse social e de outros instrumentos de política urbana, quando o uso habitacional for permitido;

VI - definição de diretrizes e instrumentos específicos para proteção ambiental e do patrimônio histórico e cultural; e

VII - definição de mecanismos para garantir a justa distribuição dos ônus e benefícios decorrentes do processo de urbanização do território de expansão urbana e a recuperação para a coletividade da valorização imobiliária resultante da ação do poder público.

$\S 10$ O projeto específico de que trata o caput deste artigo deverá ser instituído por lei municipal e atender às diretrizes do plano diretor, quando houver.

§ 20 Quando o plano diretor contemplar as exigências estabelecidas no caput, o Município ficará dispensado da elaboração do projeto específico de que trata o caput deste artigo.

§ 30 A aprovação de projetos de parcelamento do solo no novo perímetro urbano ficará condicionada à existência do projeto específico e deverá obedecer às suas disposições.

Desse modo, mesmo que tardiamente, corrigiu-se uma lacuna no ordenamento urbanístico brasileiro. Os requisitos previstos para a expansão do perímetro urbano abarcam os principais problemas da expansão urbana e podem, em tese, se forem corretamente aplicados, reduzir os impactos sociais, ambientais e econômicos da expansão urbana, bem como a especulação imobiliária resultante, e com isso melhorar a sustentabilidade das cidades brasileiras. 


\section{DENSIDADE DEMOGRÁFICA E SUSTENTABILI-} DADE

O dimensionamento do perímetro urbano está ligado a uma questão chave no debate sobre a sustentabilidade urbana: a densidade populacional. Grande parte da bibliografia aponta que cidades mais compactas, ou seja, com densidades mais elevadas, são mais sustentáveis ambientalmente do que as cidades dispersas (LEE et al., 2015; JENKS e JONES, 2010; JABAREEN, 2006). A compacidade urbana teria o efeito de aumentar a eficiência eco energética da cidade, na medida em que a isso produziria uma diminuição das distâncias a serem percorridas nos deslocamentos urbanos. Como resultado haveria a redução do consumo energético, com a diminuição dos deslocamentos, acrescido da facilitação do transporte de massa. Além disso, a compacidade facilitaria e incentivaria o deslocamento por modais não motorizados como a bicicleta ou a pé.

Outro aspecto importante avaliado em estudos sobre densidade urbana, diz respeito aos custos de implantação de infraestrutura urbana, que estão diretamente ligados ao adensamento urbano. Para Acioly e Davidson (1998):

Densidade torna-se um referencial importante para se avaliar tecnicamente e financeiramente a distribuição e consumo de terra urbana, infraestrutura e serviços públicos em uma área residencial. Em princípio, especialistas em habitação têm assumido que, quanto maior a densidade, melhor será a utilização e maximização da infraestrutura e solo urbano (ACIOLY e DAVIDSON, 1998, 16).

No entanto, não apenas a questão da otimização dos custos deve ser levada em conta na avaliação da densidade urbana. Do mesmo modo que as baixas densidades, as altas densidades podem acarretar diversos problemas urbanos, inclusive deseconomias de aglomeração. Podem-se enumerar as seguintes vantagens e desvantagens do adensamento urbano, conforme o Quadro 1.

Isso implica que, se por um lado as cidades dispersas apresentam altos custos de mobilidade urbana, uma cidade excessivamente adensada pode também apresentar altos custos de qualidade ambiental. É necessário, portanto, estabelecer quais são os padrões de densidade populacional urbana, dentro dos quais uma cidade estaria em um ótimo
Quadro 1: Vantagens e desvantagens do aumento da densidade urbana.

\begin{tabular}{l|l|}
\hline \multicolumn{1}{|c|}{ Vantagens } & \multicolumn{1}{c|}{ Desvantagens } \\
\hline Maior possibilidade de interação social & Aumento da poluição sonora \\
Menor segregação & Aumento da concentração de poluentes no ar \\
Encurtamento das distâncias & Formação de ilhas de calor \\
Incentivo ao transporte não motorizado & Menor percentual de áreas verdes \\
Maior facilidade de implantação de sistema & Sobrecarga da infraestrutura \\
de transporte público & Diminuição do sossego \\
Economia na implantação de infraestrutura & Stress social \\
e serviços públicos & \\
Menor emissão de GEE & \\
\hline
\end{tabular}

Fonte: elaborado pelo autor

ambiental, em que seria possível proporcionar uma mobilidade mais sustentável e a redução dos custos econômicos e ambientais da implantação de infraestrutura, sem, no entanto, sofrer os efeitos negativos do adensamento urbano excessivo.

Vários estudos procuraram apontar a relação entre a densidade urbana e o consumo de energia no transporte. Kenworthy e Laube (1999) avaliaram o efeito da densidade urbana sobre o uso do automóvel com em 46 cidades nos Estados Unidos, Europa, Canadá, Austrália e Ásia. O resultado foi uma correlação negativa, em que quanto maior a densidade, menor o uso de automóvel. A curva resultante (Figura 1) tem sua inflexão em torno de 50 habitantes por hectare, ou seja, acima desse valor, os ganhos com o aumento da densidade urbana tenderiam a ser progressivamente menores.

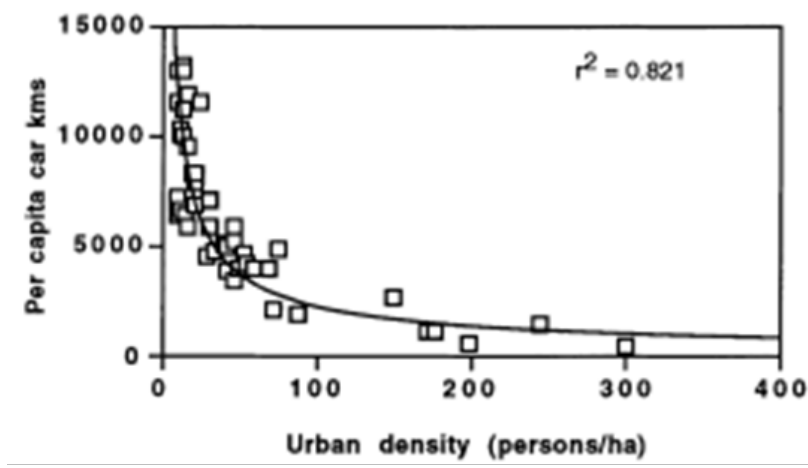

Figura 1: Densidade urbana versus uso de automóveis em 46 cidades do mundo

Fonte: Kenworthy e Laube (1999)

Frank e Laube (1994) em estudo sobre o efeito da densidade urbana na escolha de modais de transporte, concluíram que apenas a partir da faixa de 18 a 60 habitantes por acre (45 a 148 habitantes por hectare) a densidade urbana passaria a ter uma 
influência positiva significativa sobre a escolha dos modais ônibus e caminhada (Figura 2).

Com base nesses estudos, pode-se considerar um patamar em torno de 50 habitantes por hectare como a densidade populacional bruta ${ }^{2}$ mínima de uma área urbana, para que se obtenham ganhos significativos de sustentabilidade na forma urbana, do ponto de vista da mobilidade.

SHOPPING TRIPS

Modal percentages based on trip origin tracts

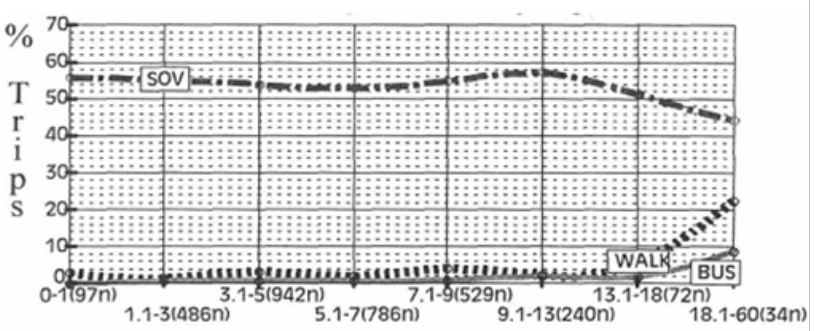

Gross Population Density Per Acre \& (\# of trips)

Figura 2: Densidade populacional versus escolha de modal de transporte.

Fonte: Frank e Pivo, 1994.

Outro fator a ser considerado sobre as densidades urbanas é seu impacto nos custos de implantação de serviços públicos. Segundo Prieto, Zofío e Alvarez (2014) os custos da implantação de infraestrutura pública como água, esgoto e pavimentação, são afetados pela densidade urbana. Para esses autores, há um "ótimo" de densidade, a partir do qual passa a haver economia de escala na implantação desses serviços. Na Tabela 1, observa-se que esses valores variam entre 28 e 44 habitantes por hectare (densidade populacional bruta).

Esse estudo, em adição àqueles sobre mobilidade e consumo de energia, apontam a densidade demográfica urbana bruta em torno de 50 habitantes por hectare, como um patamar de sustentabilidade, capaz de proporcionar uma maior propensão ao uso de modais não motorizados na mobilidade urbana, um menor consumo de energia, bem como uma economia na implantação de infraestrutrua urbana, sobretudo do saneamento.

Uma análise empírica das densidades urbanas de bairros da cidade de São Paulo pode dar uma noção do significado prático das densidades demográficas. Na Tabela 2 estão representados alguns bairros da cidade de São Paulo e as respecti- vas densidades demográficas brutas, conforme o Censo de 2010. A amostra apresenta 14 bairros de regiões e padrões urbanísticos distintos, com densidade variando ente 41 e 247 habitantes por hectare. Pode-se observar que bairros mais nobres e pouco adensados como Morumbi e Alto de Pinheiros, apresentam densidades mais baixas, em torno de 50 hab./ha. Bairros de classe média, mais centrais e de bom padrão de desenvolvimento urbano como Pinheiros e Vila Mariana, apresentam densidades pouco inferiores a 100 habitantes por hectare. Já bairros de classe média, menos centrais como Tatuapé e Casa Verde, apresentam densidades um pouco mais altas, em torno de 115 hab./hectare. Bairros populares periféricos como Itaquera e Cidade Tiradentes apresentam densidades maiores, em torno de 140 hab./ha. Por sua vez, bairros centrais, fortemente verticalizados, como Santa Cecília e República, apresentam densidades bem mais elevadas, acima de 200 hab./ha.

Tabela 1: Densidades populacionais ótimas para a provisão de infraestrutura urbana.

\begin{tabular}{c|c}
\hline Setor & Densidade ótima (ha./ha) \\
\hline Pavimentação e iluminação pública & 28,0 \\
\hline Abastecimento de água & 31,0 \\
\hline Disposição e tratamento de esgotos & 44,3 \\
\hline
\end{tabular}

Fonte: Prieto, Zofío e Alvarez (2014, p. 15)

Tabela 2: Densidade demográfica de bairros selecionados da Cidade de São Paulo, 2010.

\begin{tabular}{c|c}
\hline Bairros & Densidade (hab./ha) \\
\hline Morumbi & 41,19 \\
\hline Alto de Pinheiros & 56,00 \\
\hline Lapa & 65,74 \\
\hline Pinheiros & 91,40 \\
\hline Moema & 92,63 \\
\hline Tatuapé & 111,80 \\
\hline Casa Verde & 120,60 \\
\hline Ermelino Matarazzo & 130,59 \\
\hline Freguesia do Ó & 135,55 \\
\hline Itaquera & 140,32 \\
\hline Cidade Tiradentes & 141,00 \\
\hline Liberdade & 186,74 \\
\hline Santa Cecília & 214,66 \\
\hline República & 247,74 \\
\hline
\end{tabular}

Fonte: organizado pelo autor com base nos dados da Prefeitura do Município de São Paulo/Infocidade. 
Desse modo, pode-se perceber que o patamar de sustentabilidade de 50 habitantes por hectare não é de forma alguma exagerado, podendo ser considerado relativamente baixo, em função do o padrão de urbanização brasileiro.

\section{MATERIAIS E MÉTODOS}

\section{1 Área de estudo}

Piracicaba é uma cidade de porte médio do interior paulista, localizada a cerca de $170 \mathrm{~km}$ da capital do estado (Figura 3). O município possui uma população total de 365 mil habitantes, da qual 95\% é urbana. A população tem crescido a uma taxa de $0,75 \%$ ao ano, índice inferior à média estadual de $0,87 \%$ ao ano. A economia local é caracterizada pela indústria metal mecânica e pelo setor sucroalcooleiro.

\subsection{Metodologia: definição das métricas espaciais}

A avaliação da sustentabilidade do perímetro urbano de Piracicaba e de sua expansão será efetuada a partir do conceito de densidade sustentável e de forma urbana sustentável. Para tanto, utilizaremos um conjunto de indicadores capazes de representar importantes dimensões da forma urbana na perspectiva da sustentabilidade: ocupação, densidade, dispersão, compacidade e descontinuidade (Quadro 2).
Quadro 2: Métricas espaciais da forma urbana sustentável.

\begin{tabular}{|c|c|c|c|}
\hline Indicador & Abrev. & Fórmula & Descrição \\
\hline $\begin{array}{l}\text { Taxa de } \\
\text { Ocupação }\end{array}$ & TO & {$[$ [si) } & $\begin{array}{l}\mathrm{st}=\text { área delimitada pelo perimetro urbano; si } \\
=\text { = área da mancha urbana } \mathrm{i} ;\end{array}$ \\
\hline $\begin{array}{c}\text { Densidade } \\
\text { urbana da área } \\
\text { ocupada }\end{array}$ & $\overline{\mathrm{DU}}$ & $D U=p / s$ & $\begin{array}{l}\mathrm{p}=\text { população urbana; } \mathrm{s}=\text { área total das } \\
\text { manchas urbanas dentro do perimetro urbano }\end{array}$ \\
\hline $\begin{array}{l}\text { Densidade } \\
\text { urbana do } \\
\text { perimetro }\end{array}$ & DUP & DUP $=p / s p$ & $\begin{array}{l}\mathrm{p}=\text { população urbana; } s p=\text { área do perímetro } \\
\text { urbano }\end{array}$ \\
\hline $\begin{array}{l}\text { Indice de } \\
\text { dispersão }\end{array}$ & ID & ID & $\begin{array}{l}\mathrm{Di} \text { = distância entre o centroide da mancha } \\
\text { urbana i e o centroide da mancha urbana } \\
\text { principal; si = área da mancha i dividida pela } \\
\text { somatória das áreas de todas as manchas } \\
\text { urbanas. } \mathrm{R} \text { = raio do circulo correspondente à } \\
\text { somatória das áreas das manchas urbanas }\end{array}$ \\
\hline $\begin{array}{c}\text { Indice de } \\
\text { compacidade } \\
\text { Braga }\end{array}$ & ICB & IC & $\begin{array}{l}\text { pi = perimetro da mancha urbana } \mathrm{i} ; \mathrm{P}= \\
\text { perimetro da circunferência com área } \\
\text { equivalente à somatória de todas as manchas } \\
\text { urbanas. }\end{array}$ \\
\hline $\begin{array}{c}\text { Indice de } \\
\text { descontinuidade } \\
\text { da mancha } \\
\text { urbana }\end{array}$ & ID & $I C=P d / P$ & $\begin{array}{l}\mathrm{Pd}=\text { somatória dos perimetros das manchas } \\
\text { urbanas secundárias (descontínuas); } \mathrm{P}= \\
\text { somatória dos perimetros de todas as } \\
\text { manchas urbanas }\end{array}$ \\
\hline
\end{tabular}

Fonte: elaborado pelo autor.

\subsubsection{Ocupação}

A noção de ocupação é a mesma utilizada no zoneamento urbano: a proporção do terreno ocupada pela edificação. Neste caso, a taxa de ocupação avalia o quanto da zona urbana (a área delimitada pelo perímetro urbano) está ocupada pelas manchas urbanas. Quanto menor a taxa de ocupação, menor a sustentabilidade, pois o excesso de área urbana periférica não ocupada es-

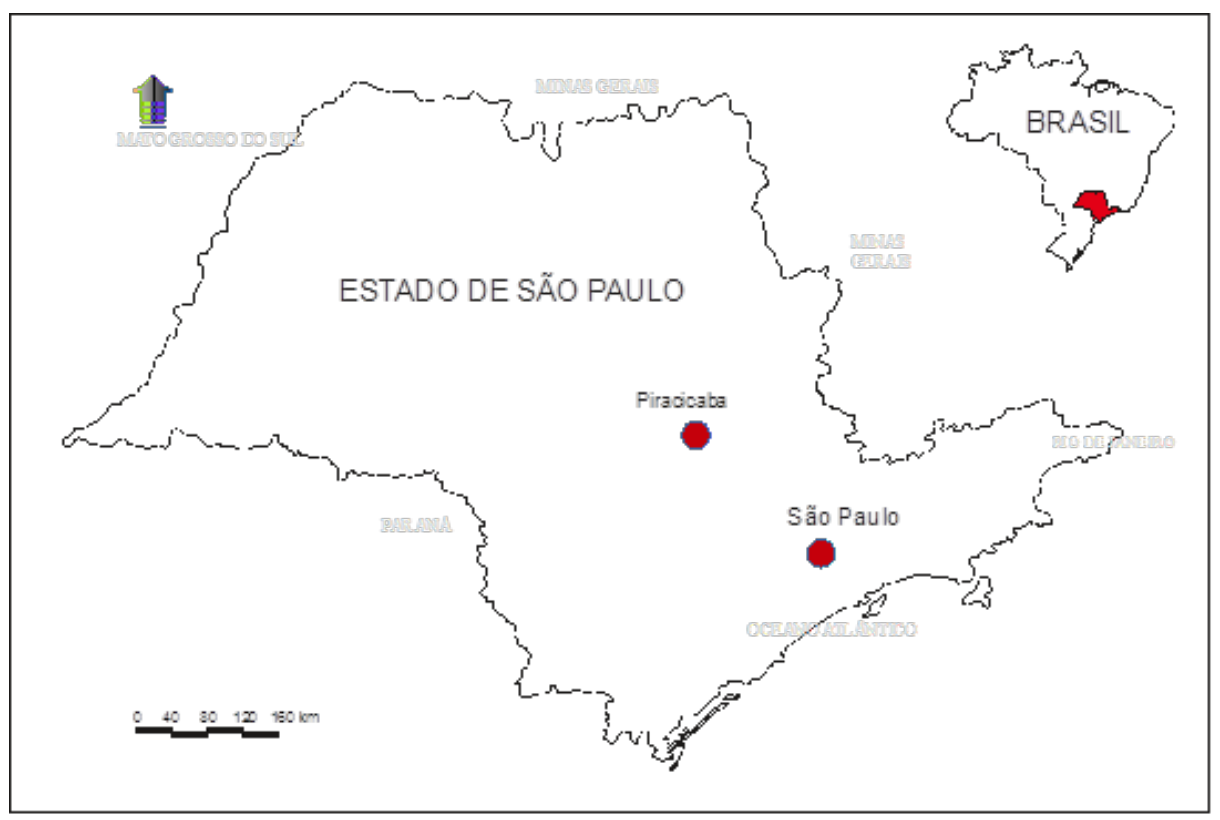

Figura 3: Localização da cidade de Piracicaba-SP Fonte: elaborado pelo autor. 
timula a fragmentação do tecido urbano e induz a novos vazios urbanos.

A taxa de ocupação urbana (TO) corresponde ao percentual da zona urbana que é ocupado pela mancha urbana, ou conjunto de manchas urbanas. $O$ índice é maior que zero e varia até 1. Quanto mais alta é a taxa, maior a ocupação da zona urbana (Figura 4).

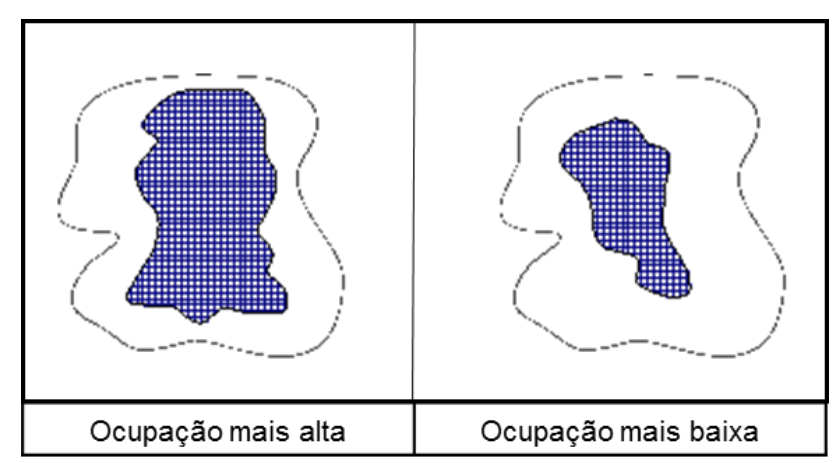

Figura 4: Figura esquemática da ocupação do perímetro urbano.

Fonte: elaborado pelo autor.

\subsubsection{Densidade urbana}

A densidade é uma dimensão muito importante da forma urbana. Cidades mais densamente ocupadas são consideradas mais sustentáveis. Isso ocorre até o limite da deseconomias de aglomeração, em que a densidade excessiva passa a gerar insustentabilidade pelos efeitos negativos da super aglomeração, como ruído, concentração de poluentes, sobrecarga da infraestrutura, violência urbana, stress urbano, entre outros.

A densidade urbana é calculada pela divisão da população urbana total pela área total das manchas urbanas. Neste caso a densidade também será avaliada para a zona urbana como um todo (Figura 5).

\subsubsection{Dispersão}

Este indicador avalia a proximidade das manchas urbanas secundárias da mancha urbana principal. Quanto mais próximas estiverem entre si, mais sustentável é a forma urbana, pois distâncias menores implicam menor consumo de energia e economia na implantação de serviços urbanos. $O$ índice de dispersão (ID) corresponde

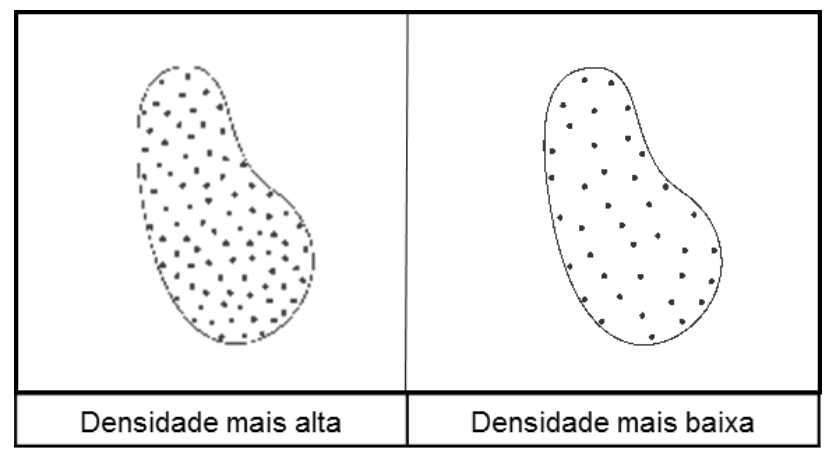

Figura 5: Figura esquemática da densidade urbana. Fonte: elaborado pelo autor.

à distância média dos centróides das manchas urbanas secundárias ao centróide da mancha urbana principal, ponderada pela área de cada mancha urbana, comparada ao raio da circunferência com área equivalente à somatória de todas as manchas urbanas. Esse índice é uma adaptação do índice utilizado por Bertaud e Maupezi (2003) para avaliar a dispersão da população em cidades. Quanto mais alto o índice, maior a dispersão das manchas urbanas. Quanto maior a dispersão, mais baixa é a sustentabilidade da forma urbana (Figura 6).

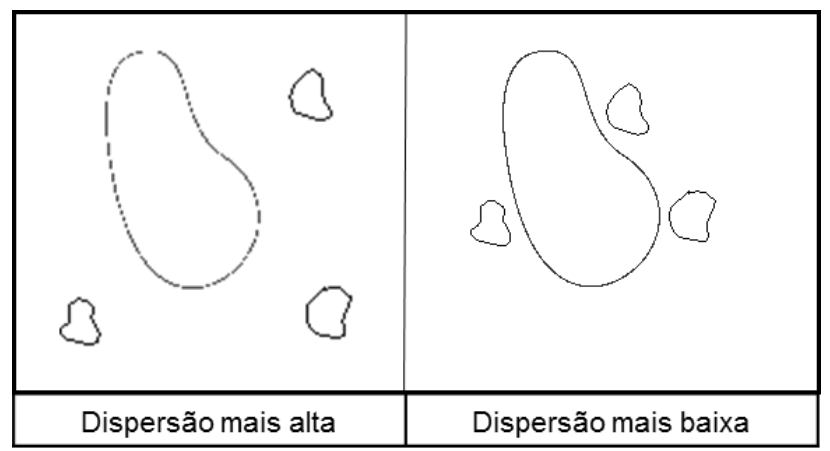

Figura 6: Figura esquemática da dispersão. Fonte: elaborado pelo autor.

\subsubsection{Compacidade}

Admite-se que a circunferência é a forma urbana que possibilita a maior compacidade para uma mesma densidade. Quanto mais próximo do perímetro da circunferência equivalente, mais compacta é a forma (Figura 7). O índice de compacidade é dado pela somatória dos perímetros das manchas urbanas dividida pelo perímetro da 
circunferência com área equivalente à somatória de todas as manchas urbanas. Quanto maior o índice, maior a compacidade. Quanto mais compacta é a forma urbana, mais alta é a sua sustentabilidade.

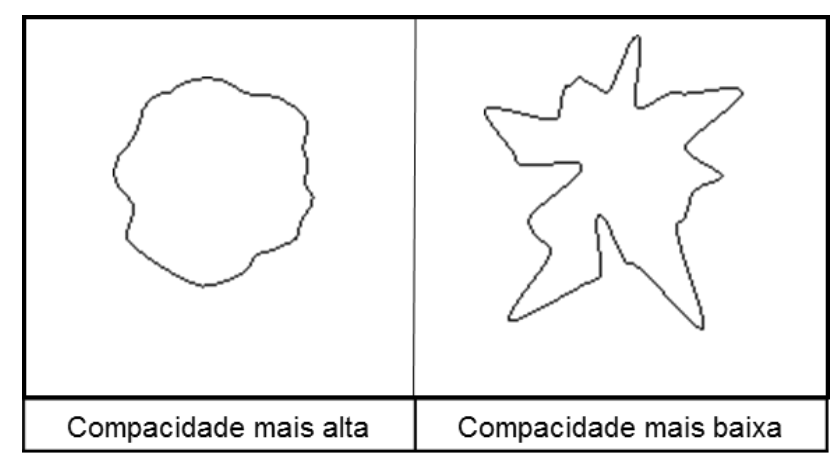

Figura 7: Figura esquemática da compacidade. Fonte: elaborado pelo autor.

\subsubsection{Descontinuidade}

O índice de descontinuidade avalia o quanto a mancha urbana é descontínua. Quanto maior a descontinuada de da mancha urbana, menor será a sua sustentabilidade. A descontinuidade é medida pela entre os perímetros das manchas urbanas secundárias e o da mancha urbana total. O valor é dado pela proporção da somatória dos perímetros das manchas urbanas secundárias em relação à somatória dos perímetros de todas as manchas urbanas. $O$ valor varia entre 0 e 1, e quanto maior, mais alta é a descontinuidade. Quando houver uma única mancha urbana, a descontinuidade é nula (Figura 8). Quanto mais alta é a descontinuidade, mais baixa é a sustentabilidade da forma urbana.

\section{RESULTADOS}

Em 2000, o perímetro urbano de Piracicaba (Figura 9) abrangia uma área de 16.400 ha, abrigando uma população e 316 mil habitantes, resultando em uma densidade bruta de menos de 20 habitantes por hectare. Essa situação, conforme Goulart e Terci (2014), levou a que os estudos formulados em 2003 e 2004 para a elaboração do Plano Diretor recomendassem o seu congelamento. No entanto, tal fato não ocorreu e, entre 2000 e 2013, o perímetro urbano de Piracicaba foi alterado nove vezes, acrescentando mais de 5.000 hectares à zona urbana, que passou a abranger uma área de mais de 21.500 hectares (Tabela 3 e Figura 9). Isso significou uma ampliação do perímetro da ordem e $31 \%$, enquanto a população urbana teve um incremento e apenas $15 \%$. Isso demonstra um evidente super dimensionamento da zona urbana piracicabana e uma redução da sustentabilidade urbana.

Tabela 3: Piracicaba-SP Incremento da área urbana e da população urbana entre 2000 e 2013.

\begin{tabular}{l|r|r|r}
\hline & \multicolumn{1}{|c|}{2000} & \multicolumn{1}{c|}{2013} & Incremento (\%) \\
\hline Zona urbana (ha) & 16.404 & 21.589 & $31,6 \%$ \\
\hline População urbana $^{*}$ & 316.876 & 365.125 & $15,2 \%$ \\
\hline
\end{tabular}

Fonte: Fundação SEADE / elaborado pelo autor.

A aplicação dos indicadores de forma urbana à cidade de Piracicaba para os anos de 2000 e 2013 revela uma queda no grau de sustentabilidade urbana (Tabela 4). A taxa de ocupação da zona urbana caiu de $57 \%$ para $51 \%$. Isso significa que quase metade da zona urbana estava ociosa em 2013. A densidade urbana bruta, considerando toda a área do perímetro, caiu de 19,7 para 16,9 habitantes por hectare. Considerando apenas a zona urbana ocupada (mancha

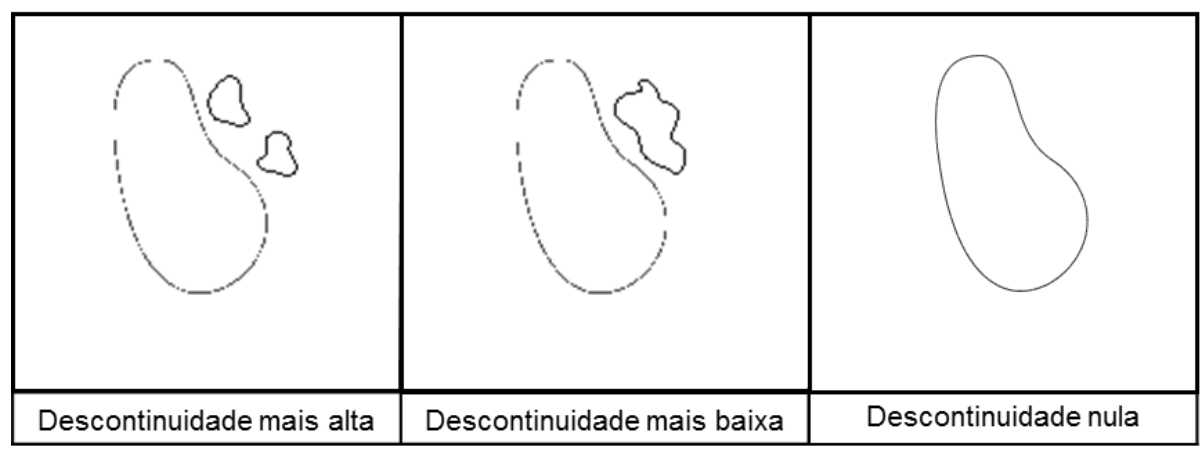

Figura 8: Figura esquemática da descontinuidade Fonte: elaborado pelo autor. 


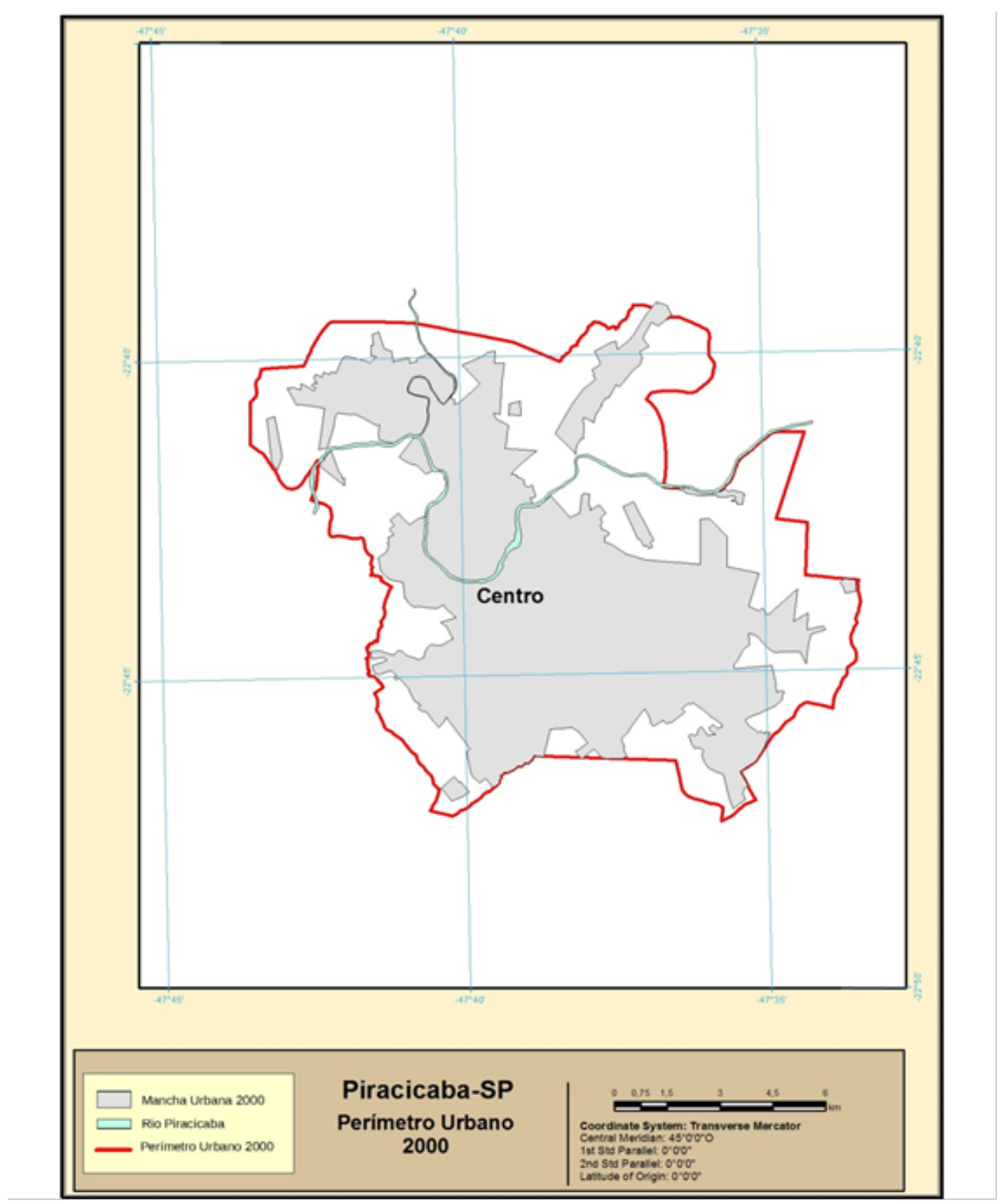

Figura 9: Piracicaba-SP. Perímetro urbano 2000.

Fonte: elaborado pelo autor.

urbana) esse índice diminuiu de 34,8\% para 33,2\%. São densidades urbanas muito baixas. Considerando a densidade urbana básica de 50 hab./ha, pode-se avaliar que a zona urbana teria capacidade para suportar, em 2013, uma população de pelo menos um milhão de habitantes, em bases sustentáveis.

Isso é corroborado com os valores observados no Índice de Compacidade. Em 2000 esse índice era de 0,27 , muito baixo, considerando-se que a escala vai até um. Não obstante, em 2013, esse valor caiu mais ainda, passando a 0,20, o que demonstra que a zona urbana tornou-se ainda mais rarefeita.
Acompanhando a tendência demonstrada pelo o índice de Compacidade, o Índice de Descontinuidade cresceu significativamente, passando de 0,26 para 0,41 , o que demonstra um aumento expressivo na fragmentação da mancha urbana. O Índice de Dispersão, que mostra a dispersão dos fragmentos do tecido urbano, no entanto, não acompanhou a tendência revelada pelos demais índices, apresentando uma queda, passando de 1,18 para 1,16. A variação é muito pequena, mas negativa, o que revela que os fragmentos da mancha urbana ficaram menos dispersos, ou seja, a distância média entre os 


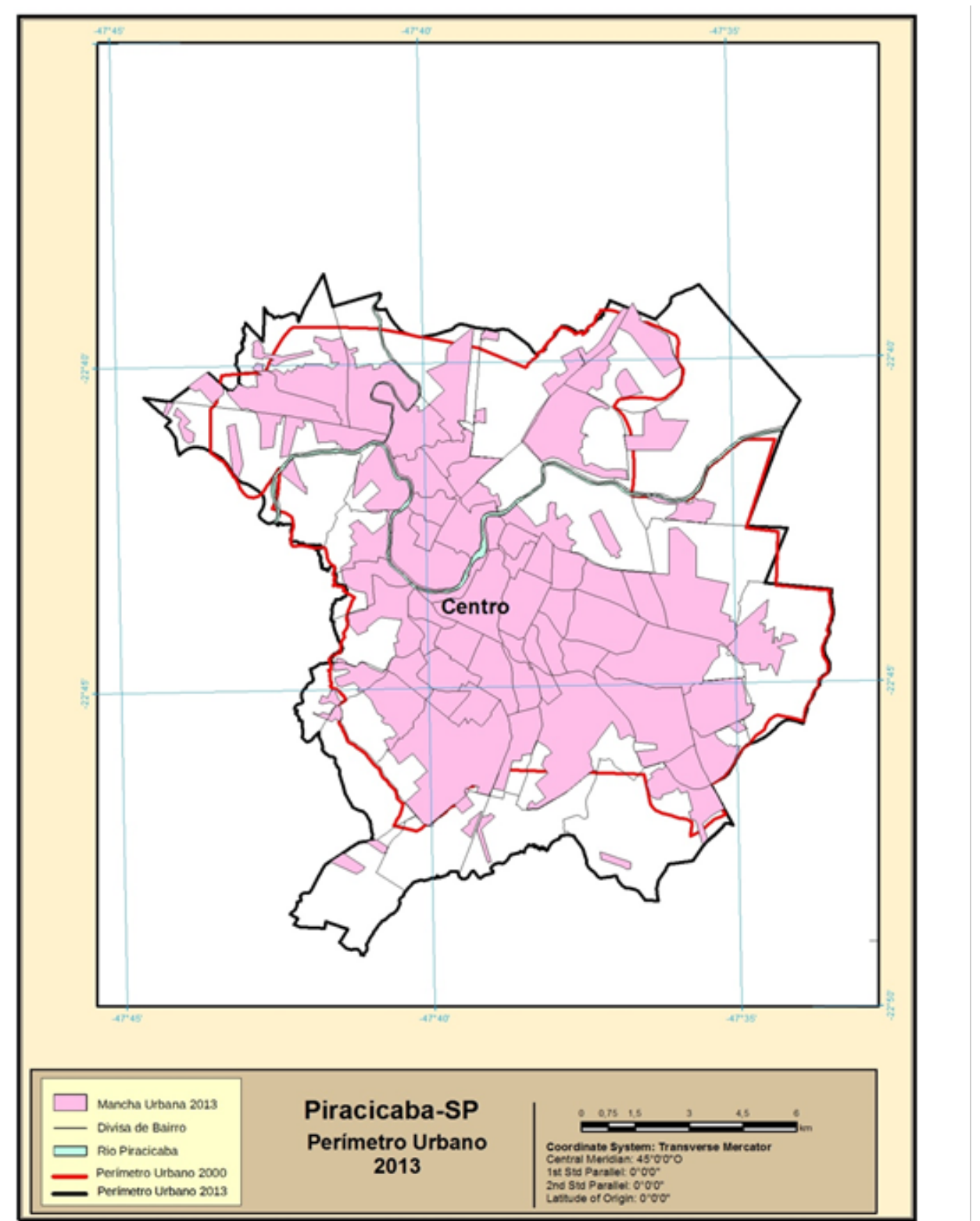

Figura 10: Piracicaba - Perímetro Urbano 2013

Fonte: elaborado pelo autor.

Tabela 4: Piracicaba - Indicadores de forma urbana - 2000 e 2013

\begin{tabular}{|c|c|c|c|}
\hline Indicador & 2000 & 2013 & Incremento (\%) \\
\hline $\begin{array}{l}\text { Taxa de Ocupação da zona } \\
\text { urbana }(\%)\end{array}$ & $57 \%$ & $51 \%$ & $-10,0 \%$ \\
\hline $\begin{array}{l}\text { Densidade da urbana bruta } \\
\text { (hab./ha) }\end{array}$ & 19,7 & 16,9 & $-14,2 \%$ \\
\hline $\begin{array}{l}\text { Densidade bruta a mancha } \\
\text { urbana (zona urbana } \\
\text { ocupada) (hab./ha) }\end{array}$ & 34,8 & 33,2 & $-4,7 \%$ \\
\hline Índice de Compacidade & 0,27 & 0,20 & $-25,9 \%$ \\
\hline Índice de Descontinuidade & 0,26 & 0,41 & $57,7 \%$ \\
\hline Índice de Dispersão & 1,18 & 1,16 & $-1,7 \%$ \\
\hline
\end{tabular}

Fonte: elaborado pelo autor. mesmos diminuiu. Isso pode ser explicado pela implantação de novos fragmentos urbanos nos interstícios da zona urbana, o que fez com que os fragmentos ficassem um pouco mais próximos entre si, como se pode observar na Figura 10. No geral, dos seis indicadores avaliados, cinco apontaram, além de padrões baixos de sustentabilidade, uma piora do quadro no período analisado.

\section{CONCLUSÕES}

A forma urbana é um dos parâmetros aceitos 
majoritariamente pela bibliografia especializada para a avaliação da sustentabilidade urbana. Considera-se que uma cidade rarefeita e fragmentada apresenta menor grau de sustentabilidade, na medida em que é menos eficiente eco energeticamente, por favorecer o desperdício de recursos prima e o maior consumo energético, sobretudo o relativo à mobilidade urbana.

Os indicadores desenvolvidos avaliaram aspectos da forma urbana ligados à ocupação, densidade urbana, dispersão, compacidade e descontinuidade da mancha urbana. O teste aplicado na cidade de Piracicaba para a avaliação da evolução dom perímetro urbano entre 2000 e 2013 permitiu a avaliação desses indicadores, bem como da sustentabilidade do processo.

Os resultados indicaram que o perímetro urbano de Piracicaba não atende aos padrões de sustentabilidade do ponto de vista de uma forma urbana sustentável. A cidade apresenta uma densidade populacional muito baixa, bastante aquém do patamar desejável de 50 habitantes por hectares a qual ainda diminuiu no período. $\mathrm{O}$ tecido urbano apresenta-se também bastante fragmentado, com queda do grau de compacidade e aumento do grau de dispersão no período avaliado. Isso indica que o processo de crescimento urbano de Piracicaba está se dando de maneira insustentável e que o perímetro urbano não só está superdimensionado, como vem crescendo insustentavelmente. Os indicadores desenvolvidos e utilizados demonstraram-se adequados e consistentes como ferramentas para a avaliação da sustentabilidade de perímetros urbanos.

\section{REFERÊNCIAS BIBLIOGRÁFICAS}

ACIOLY, C.; DAVIDSON, F. Densidade urbana: um instrumento de planejamento e gestão urbana. Rio de Janeiro: Mauad, 1998.

BERTAUD, A.; MAUPEZZI, S. The Spatial Distribution of Population in 48 World Cities: Implications for Economies in Transition. The Center for Urban Land Economics Research-The University of Wisconsin. 2003. Disponível em: http://alainbertaud.com/AB_Files/ Spatia_\%20Distribution_of_Pop_\%2050_\%20Cities.pdf
COSTA, E. M. da.; ROCHA, J.; RODRIGUES, M. Urban Form Analysis Employing Land Cover And Spatial Metrics - The Case Of The Lisbon Metropolitan Area. SCIV, Barcelona, Espanha, 2009. Disponível em: http://upcommons.upc.edu/revistes/bitstream/2099/11349/1/01_PROCEEDINGS_ M1_10_0023.pdf

FRANK, L.D.; PIVO, G. The Impacts of Mixed Use and Density on the Utilization of Three Modes of Travel: The Single Occupant Vehicle, Transit, and Walking. Transportation Research Record, 1466, pp. 44-52. 1994.

HUANG, J., LU, X.X., SELLERS, J.M. A global comparative analysis of urban form: applying spatial metrics and remote sensing. Landscape and Urban Planning, 82 (4), 2007.

JABAREEN, Y. R. Sustainable Urban Forms : Their Typologies, Models, and Concepts. Journal of Planning Education and Research, 26: 38, 2006.

JENKS, M.; JONES, C. (Eds). Dimensions of the Sustainable City. London/New York: Springer, 2010.

KENWORTHY, J.R.; LAUBE, F.B. Patterns of automobile dependence in cities: an international overview of key physical and economic dimensions with some implications for urban policy. Transportation Research Part A, 33, p. 691-723, 1999.

LEE, J; KURISU, K.; AN, K.; HANAKI, K. Japan Development of the compact city index and its application to Japanese cities. Urban Studies, Vol. 52(6) 10541070, 2015.

PRIETO, A.M.; ZOFÍO, J.L.; ALVAREZ, I. Cost economies, urban patterns and population density: The case of public infrastructure for basic utilities. Papers in Regional Science, 17 jan 2014. doi:10.1111/pirs.12096. Disponível em: http://onlinelibrary.wiley.com/ doi/10.1111/pirs.12096/epdf

SILVA, Antonio N.R. da; FERRAZ, Antonio C. P. Densidades Urbanas x Custos dos Serviços Públicos - Análise do Caso de São Carlos. Revista de Administração Municipal, Rio de Janeiro, IBAM, v. 38,n.199. abr/jun 1991. 
SILVA, J.A. Direito urbanístico brasileiro. Segunda Edição. São Paulo: Malheiros, 1995.

STEEMERS, K. Energy and the city: density, buildings and transport. Energy and Buildings, 35, 3-14, 2003.

TERIMAN, S. Measuring neighborhood sustainability: a comparative analysis of residential types in Malaysia [Tese de Doutorado]. Brisbane (QLD): Queensland University of Technology School of Civil Engineering and the Built Environment, 2012.

\title{
Notas de Fim:
}

1- Trabalho realizado com o apoio da FAPESP (Processo 2013/02853-0)

2- Considera-se nesse tipo de análise sempre a densidade bruta, não a líquida, pois esta, ao excluir os espaços livres, subestima o fator distância.

Correspondência do autor:

\author{
Roberto Braga \\ e-mail: rbraga@rc.unesp.br
}

Artigo recebido em: 14/12/2015

Aceito para publicação em: 17/ 6/2016 